DOI: $10.20472 / B M .2015 .3 .1 .001$

\title{
GENERATION Y AT WORK: INSIGHT FROM EXPERIENCES IN THE HOTEL SECTOR
}

\section{ROBERT LEWIS}

\begin{abstract}
:
'Generation Y,' according to recent literature, refers to people born between 1980 and 1990. Participants in the study used for this paper (aged between 23 and 33) fit into this category at the time of data collection (in 2013). The literature suggests that generation $Y$ is reliant on feedback at work, a need for immediate results and a desire for personal satisfaction from work. From a managerial standpoint, the literature indicates that generation $Y$ seeks high levels of communication at work and perceives lower hierarchical barriers. This study explores the perceptions of generation $Y$ working in the hotel industry within these dimensions. 80 generation $Y$ university students volunteered to answer open-ended questions in questionnaires. Participants had at least six months' work experience in hotels as part of their curriculum. Open-coding was used to extract key quotes from raw data. Findings reveal that the group studied emphasised the importance of self-achievement, congruence of work with personal values and open communication. The conceptualisation of generation Y's perceptions of work in the hotel sector reveals a more fragmented understanding of time and unconventional views of careers.
\end{abstract}

\section{Keywords:}

Careers, Generation Y, Hotels, Work Expectations, Work Relationships

JEL Classification: J24

\section{Authors:}

ROBERT LEWIS, Les Roches Gruyère University of Applied Sciences, Switzerland, Email: ralewis@gmail.com

\section{Citation:}

ROBERT LEWIS (2015). Generation Y at work: insight from experiences in the hotel sector. International Journal of Business and Management, Vol. III(1), pp. 1-17., 10.20472/BM.2015.3.1.001 


\section{Introduction}

Generations are characterised by groups of people within a specific time span (Josiam, Devine, Baum, Crutsinger and Reynolds, 2007). These periods of common life experiences have often been identified based on historical considerations. One example is the 'baby boom' generation (ibid). Research has also focused on the characteristics of generations to discuss their differences with other generations (Erickson, 2008). Though debated, a generation can be defined as a specific period of time during which people can be identified by common traits (ibid; Fenick, Scott-Halsell and Hashimoto, 2011). This paper investigates the experiences of a generation often called generation ' $Y$.'

Despite attempts to establish parameters to understand the identity of generation $\mathrm{Y}$, the literature generally refers to people born approximately between 1980 and 1990 (Erickson, 2008; Fenich et al., 2011; Josiam et al., 2007, Tulgan, 2009). Generation Y has also been referred to as the millennial generation (Erickson, 2008; Ng, Schweitzer and Lyons, 2010). There are numerous studies, which attempt to understand the characteristics of generation $Y$, such as a self-centred vision (ibid; Tulgan, 2009). There is a growing body of knowledge that probes into the effects of generation $Y$ at work, such as low importance of hierarchy and demanding career expectations (ibid). Within this branch, there are an increasing number of investigations on the experiences of generation $Y$ workers in the service industry, notably hotels.

It is increasingly common to find different generations working together (Twenge and Campbell, 2008). With the introduction of generation $Y$ into the work force, the literature has identified a cultural 'clash' between generation $Y$ with older generations (ibid; Tulgan, 2009). This may be due to the current take up of the use of Information Technology (IT). One example is the use of smartphones and their synchronous communication features (e.g., texting)), which has been widely adopted by generation $Y$, in contrast to their older counterparts (Tulgan, 2009).

Furthermore, the service sector, which requires high levels of human interaction (Baum, 2006; Michel, Kavanagh and Tracy, 2012), has grown significantly in recent decades (Solnet and Kralj, 2011). The desires and needs of generation $Y$ in service industries constitute a new dimension which challenges understandings of work-related behaviour in organisations. This paper focuses on the evaluation of work experiences of people from generation $\mathrm{Y}$ in the hotel sector.

\section{$2 \quad$ Literature review}

\section{Attempts to define generation $Y$}

Though many academic studies have attempted to define generation $Y$ (Erickson, 2008; Josiam et al., 2007; Michel, Kavanaugh and Tracy, 2012; Ng et al., 2010; Tulgan, 2009), 
it is more common for researchers to discuss observations which influence our understanding of the concept (Twenge and Campbell, 2008). These observations include what behaviour is common to generation $Y$ (ibid), how generation $Y$ understands the workplace (Twenge, Campbell, Hoffman and Lance, 2010; Tulgan, 2009) and how generation $Y$ 'thinks' (Erickson, 2008). Discussions from authors on these dimensions underscore generation Y's tendency to have self-centred perceptions ( $\mathrm{Ng}$ et al., 2010; Twenge et al., 2010; Tulgan, 2009).

Despite the previous arguments, the literature does not reveal clear definitions, but rather elucidates common behaviours which help identify people from generation $Y$. This has emanated from generational culture conflict between generation $\mathrm{Y}$ and older generations (Tulgan, 2009). This approach can be influenced by outside factors, such as societal trends, such as the growth of inter-generational workforces (ibid). From a sociological standpoint, the study of generations, and in particular generation Y, can contribute to the understanding of how social factors, such as hierarchical perceptions (Schein, 2010), affect generational groups in work settings. For the purposes of this paper, generation $Y$ refers to study participants, born between 1980 and 1993, at the time of data collection in 2013.

\section{Traits}

Generation $Y$ exhibits an increased need for feedback and open communication at work (Eisner, 2005; Martin, 2005; Twenge and Campbell, 2008). This is also manifested by generation Y's desire for communication at a fast pace ( $\mathrm{Ng}$ et al., 2010). Examples of this trait have been identified in studies (Martin, 2005; Solnet and Hood, 2008; Twenge and Campbell, 2008) and, more specifically, in relation to how generation $Y$ interacts with colleagues and managers in hotels (Solnet and Hood, 2008). The hotel sector, in particular, places emphasis on the need to operate with employees from different generations (Twenge et al., 2010).

The need for 'immediacy' can be linked to the use of electronic devices, such as email and texting, as a primary means of communication for generation $Y$ (Eisner, 2005; Erickson, 2008; Tulgan, 2009). There is anecdotal evidence (Martin, 2005) that shows how managers of generation $Y$ employees communicate at a slower pace. In the hospitality context, such as in hotel work, the interaction of employees with their colleagues and managers is a key feature of job functions due to the nature of providing face-to-face service to guests (Adams, 1976).

Despite the above arguments, the literature does not reveal how conscious generation $Y$ is of its need to adapt to the communication needs of its colleagues and managers from other generations (Barron, Maxell, Broadridge and Ogden, 2007; Cennamo and Gardner, 2008). Academic studies provide evidence which emphasises a 'self-centred' perception of generation Y (Maxwell and Broadbridge, 2010; Ng et al., 2010; Tulgan, 2009). This 
suggests that generation $\mathrm{Y}$ can experience difficulty understanding the communication needs of its colleagues and/or line managers.

\section{Values}

The literature underscores generation Y's desire for structured career paths $(\mathrm{Ng}$ et al., 2010; Terjesen, Vinnicombe and Freeman, 2007, Tulgan, 2009). This is complemented by evidence which suggests that generation $Y$ needs to grow in its careers quickly (Gursoy, Maier and Chi, 2008; Solnet and Hood, 2008; Solnet et al., 2012; Tulgan, 2009). Nevertheless, this is in contrast to traditional career paths in organisations based on hierarchy. From a temporal perspective, Viard (2011) points out that today workers experience scattered career paths due to a more fragmented organisation of work and social time. Moreover, organisational norms in many large hotel organisations require employees to spend significant periods of time in various functions before being promoted (Solnet and Hood, 2008). An emphasis on hotel employment has traditionally been made on the importance of experiences (Baum, 2006). The career-related values of generation $Y$ can be incongruous with those displayed by many of the organisations currently employing them. In hotels, where tradition has often influenced the context of employee relations, this has become a prevalent issue debated in the literature (Josiam et al., 2007; Maxwell and Broadbridge, 2010; Solnet and Kralj, 2011; Tulgan 2009).

Studies have shown that generation $Y$ needs to gain meaning from work (Barron et al., 2007; Eisner, 2005; $\mathrm{Ng}$ et al., 2010). Meaning is translated into work activities that are congruous with social values (Tulgan, 2009; Twenge et al., 2010). Another branch of the literature reveals generation Y's need for increased work-life balance (Maxwell and Broadbridge, 2010; Tulgan, 2009). This generally refers to the need for generation $Y$ to acquire time from work for personal activities (ibid). In the hotel context, the 'conciliation' between workers' desires for increased work-life balance remains relatively unconventional. This implies that traditional organisational contexts found in hotels are not adapted to certain needs of generation $\mathrm{Y}$.

From a sociological perspective, Merton (1957), in his role set theory, argues that workers seek to cope with work- and non-work-related roles to achieve perceived satisfaction. In this vein, and despite improvements from one large hotel group in Asia to adapt to generational differences for workers through an on-site 'employee centre' (Lewis and Mottier, 2012), there are few examples of how hotels seek to increase work-life balance initiatives to attract and/or retain employees.

\section{Work relationships}

The literature discusses how generation $Y$ is more demanding of its line managers (Gursoy et al., 2008; Martin, 2005; Twenge and Campbell, 2008; Tulgan, 2009) in terms of communication. The relationships that generation $\mathrm{Y}$ desire are open and direct 
(Eisner, 2005; Maxwell and Broadbridge, 2010; $\mathrm{Ng}$ et al., 2010; Tulgan, 2009). This can be at odds with older generations which are not as used to frank discussions with subordinates (Martin, 2005; Tulgan, 2009). It is also unclear how organisational cultures affect this. Generation $Y$ perceives fewer hierarchical barriers when giving its opinions or when making suggestions (Martin, 2005). Again, this can be at odds with traditional management methods which emphasise distance between employee levels and perceived status, often related to organisational position (Schein, 2010). Moreover, hotel work has traditionally focused on adapting to organisational cultures and learning skills through experience (Baum, 2006). In this vein, work experiences in hotels have been conventional sources for building competencies and careers. Developing and maintaining relationships at work are inherently linked to this. These arguments reveal that generation Y's perceptions of work relationships contrast with current understandings.

\section{Research questions}

The following research questions emerged from the literature covered.

1) What are the predominant traits of generation $Y$ employees in hotels?

2) What are the predominant values of generation $Y$ employees in hotels?

3) How do generation $Y$ employees perceive their work relationships in hotels?

One study in the literature used a large sample $(n=504)$ to investigate generational differences at work (Cennamo and Gardner, 2008). The study for this paper evaluated themes from the literature in an exploratory fashion on a much smaller group of people to gain more profound understanding on their experiences in hotels. The above research questions for this paper were used to develop sets of open-ended questions used in questionnaires to capture experiences of 80 respondents, which is discussed in the following section.

\section{Methodology}

\section{Pilot test}

Themes, identified in the literature, were used to identify questions to investigate, which is supported by Denzin and Lincoln (1998). This qualitative approach aimed at retrieving insight from themes and, at the same time, exploring new ones. For the pilot test, a draft questionnaire was developed and distributed to six volunteers.

The draft questionnaire contained six open-ended questions:

1) Question one asked for age, nationality and gender.

2) Question two asked how long the participant had experience working in hotels, with an option to answer 'none,' if applicable. 
3) Question three asked participants if they need feedback from managers/colleagues and to provide examples.

4) Question four focused on the meaning of work for participants. It asked candidates how important it is for a job to 'match' their values and to provide examples. The second part of this question asked participants if they are attracted to work in an environment that matches their values. It also asked them to identify examples of values. This section of the questionnaire provided example values (honesty, sharing, and trust).

5) Question five asked participants if they choose a job because it brings personal satisfaction. It also asked them to provide examples of how work can provide personal satisfaction.

6) Question six asked participants how important it is for them to choose an employer who offers a structured career and asked them to explain why.

Draft questionnaires were distributed in-person to a group of six graduate students at a Swiss university one afternoon. All were between 23 and 30 years old. Students were asked to write any comments on the draft that were not related to the question itself, such as feedback on a question's wording or any potential misunderstandings. All participation was anonymous and confidential. Respondents were under no pressure to participate and were all volunteers.

There were few language difficulties observed. Nevertheless, some vocabulary was altered to 'fit' with the understanding of participants. Moreover, some candidates asked for specific examples of values, which were subsequently added to question four (see above).

The objective of using six open-ended questions was to retrieve examples of experiences of study participants that could provide illustrations. Despite the potential 'directive' aspect of the questionnaire (which can be argued is inherent to a semi-structured questionnaire), questions were phrased in a neutral fashion to avoid 'leading' participants. The finalised questionnaire contained the six original open-ended questions and previously-discussed alterations.

\section{Finalised questionnaire administration}

Questionnaire respondents were all university students in Switzerland, specialised in service management, who each had over six months work experience in hotels. This work experience was part of their curriculum. All students were in their third and fourth years of study. The students took part in the study during an afternoon break after their classes had finished during autumn 2013.

Before filling out questionnaires, the researcher introduced the purpose of the study and stated the guarantee of anonymity and confidentiality. Respondents were under no 
pressure to participate and were all volunteers. The researcher was also available during the session to answer any questions or provide help. There were no questions about content. By contrast, some participants asked the researcher for examples for answers. The participants took between 30 and 45 minutes to complete the questionnaire.

\section{Participant profiles}

The sample $(n=80)$ studied was highly international, with over 32 nationalities represented. The most dominant nationalities were Chinese $(n=14)$ and French $(n=7)$. All others were more evenly dispersed. All had been educated at university level in the English language. They have all studied hotel management in Switzerland and have worked for over six months in hotel job functions.

There were 37 females and 43 males who participated in the study. Their experience working in hotel functions ranged from 6 months to 72 months, with an average of 13 months. The average age was 23 , with a range from 19 to 29. Though few students fell outside of the 'generation $Y$ ' age range established (aged approximately 23 to 33 in 2013), all students were included due to their similar experiences and interaction with their peers.

\section{Data analysis}

After questionnaires were collected, they were transcribed and labelled into Word documents. Study participants' questionnaires were labelled with numbers (e.g. respondent one was recorded as 'R1'). Respondents' answers to each question were keyed into each corresponding Word documents (each Word document represented one question).

Open coding was used to sort through data to identify themes and to allow patterns to emerge. Codes, or themes, were extracted from replies through a sifting process (Richards, 2009). This process was repeated until final themes were identified. The entire data set was reviewed (with all question replies) because it allowed identifying any 'crossover' of themes. This suggests that answers to questions could fall outside of the scope of the question's corresponding theme. This allowed answers to be broken down into chunks of words or parts of sentences, called Meaning Units, or MUs, according to Giorgi (1994). MUs are used as quotes in this paper to strengthen discussions through illustrations.

As a rough estimate, approximately one-third of themes that emerged from commonalities in raw data were sorted into subthemes. Quotes that best illustrated their respective themes were extracted for discussions in this paper. Whilst sifting through raw data to sort them into themes and related subthemes, frequencies of replies were not the focus, but rather key illustrations to provide depth and insight. 
Themes from the raw data set fit predominantly into the categories of traits, values and work relationships. These themes are the main headings for discussions of findings in this paper. For example, 'satisfaction' and 'goal-setting' were predominant subthemes that emerged from the raw data related to 'traits.' The following sections use quotes, or MUs, embedded in discussions, to 'tell the story' of the material retrieved. The findings in this paper are restricted to the number of selected quotes from participant replies. Quotes are not intended to provide generalisation, but rather 'snapshots' into the perceptions of this unique co-hort of international students with similar professional experience in a hotel context.

\section{$4 \quad$ Findings}

Perceptions of traits

Importance of satisfaction from work

Respondents stated that receiving acknowledgement was important.

When you finish the task and get acknowledgement from others. (respondent 5).

A need for a sense of fulfilment from work was also expressed in findings.

I get fulfilment from results. Numbers and sales provided fulfilment since whenever I was able to sell things or get new clients it gave me a sense of selfachievement. (respondent 12).

Overall, respondents' replies showed how work influenced their perceived satisfaction.

If you do what you are passionate for, I think you gain personal satisfaction. I would only choose jobs what I can be myself and work for the person/same company I can stand behind. I must be persuaded by the company or product to be satisfied. (respondent 69).

The above citations reveal that it is important for participants in this study to have interaction with colleagues at work. The replies suggest that feedback received is not only enriching, but also influences and re-enforces perceptions of organisational citizenship.

Effects of goal-setting

Replies focused on the importance of having goals to structure perceptions of work advancement. 
It is necessary if your goal is to work long in the company. It is important to know where you could go. You know why you are working! (respondent 14).

Respondents illustrated the necessity of goals at work for planning purposes.

It is important to have goals that have to be achieved in order to keep growing. I believe a career plan is a way of motivating the employee to perform well. (respondent 20).

Because it is goals that motivate you to reach the milestones listed in the structured career curriculum. (respondent 55).

Goals also shaped respondents' perceptions of the future.

It is very important because I believe in long-term goals rather than immediate satisfaction. (respondent 17).

This enables you to know that your goal is and know what to look towards in the future. With a structured career from the start, you can start early to plan your way up and focus only on the essentials to reaching that goal rather than wasting time dilly-dallying on other unimportant factors that won't necessarily help you meet your expected target. (respondent 80).

Above replies highlight that participants prefer more structured career paths where their efforts can be compensated. Career paths in hotels are traditionally focused on longterm acquiring of skills. This parallels with replies that suggest that it is important to perceive meaning from work accomplished. This reveals that work, for participants in this study, is a concept that covers work and non-work life. Moreover, replies suggest that contributions at work have value in non-work life, such as the perception of 'growing.'

\section{Perceptions of values}

Respect

Respect on all levels was deemed valuable.

It is important for me that respect is always experienced between myself and customers or myself and colleagues, as well as honesty. (respondent 2).

Work motivation was linked to respect.

In fact, if it (work) does not match my values I would not feel motivated. In one of the outlets I worked the manager was disrespectful. I looked forward to leaving the outlet. (respondent 17). 
Respect was considered important in work relationships.

I like to please guests. I would like to work for people that feel the same. I need to work for respectful people - I left a company because it was disrespectful. (respondent 42).

Above replies shed light on the importance of integrity at work, in terms of working in a respectful environment. Replies further suggest that the understanding of a respectful 'guest' experience in a hotel context can be extended and translated into a respectful 'employee' experience. This reveals that effective work relationships can contribute to and foster respectful work environments.

Importance of work-related values' congruence with personal values

Ethics were linked to personal values.

Ethics are essential. If I feel bad and doubtful regarding the unfairness of activities for my jobs I will probably resign. Fairness to the customer and colleagues are essential to achieve good work and a good company culture. (respondent 1).

Respondents separated perceptions of values into implicit and explicit factors.

In order to achieve job satisfaction the job itself should match your internal and external factors. Values being part of the internal factors will determine if you are comfortable with your job. Example, employee that has been explained the quality standard and needs self-fulfilment will know challenges and not be comfortable as a trainee. (respondent 35).

Gaining meaning from work was emphasised in replies.

I am fully dedicated to my work if I identify my values with the work being done. Providing good service and value-for-money products are meaningful for me. If I were asked to do something not up to standard, I would not be happy about the work. (respondent 65).

I would not take a job that questions my moral values. For example, organisations that work with 'underhand' or 'under the table' method. I would also refuse to work for a company who has methods against human rights or animal rights. (respondent 74).

The influence of values in the work environment was highlighted. 
It is very important that my role and responsibilities at the workplace are aligned with my values. I value mutual respect between colleagues and value a workplace that strives to create a friendly environment. (respondent 76).

Above comments suggest that personal values spill over into perceptions of work behaviour. Furthermore, this reveals that employees can be demanding in terms of their expectations from employers. In other words, this indicates that there is a theoretical threshold at which employees would consider an employer incompatible because of incongruence with their value sets.

\section{Perceptions of work relationships}

Feedback

Respondents revealed a reliance on feedback for self-improvement.

In any situation where I have struggled or had to make decisions on my own, a problem or deal with a situation. I then need feedback to assess my performance and further improve myself. Working in the banqueting department, I had to deal with a client that required a last minute 'cocktail reception' after his business conference, for 70 persons. None of the other banqueting rooms were available. I decided to set up the cocktail in the hotel corridor, outside of the conference room. The feedback I got was very useful to help me identify the good and negative points of my organisation. (respondent 33).

Respondents discussed a need for feedback on a continuous basis.

Feedback would always be great at any time. After a long day of work, it would be nice if managers give feedback on my performance. For colleagues it would be great to have feedback during work. Every day, when I worked at the bar at closing time when we finished cleaning, my colleagues, managers and I would all sit together with a drink and talk about the performance. What went wrong, how to improve, recognition. (respondent 52).

When I just started for example at the end of my first month, I would appreciate it if my manager/colleagues would evaluate my performance and tell me what I did well and what I should improve. (respondent 74).

Respondents expressed cultural implications of feedback, illustrated in face-to-face and non-face-to-face communication patterns.

Yes. I like to communicate with people face-to-face not just sit in front of a computer. (respondent 5). 
Having worked in China, I realised the workplace has a lot of hidden hostility from the service staff to the management, which can hinder the efficiency of operations. (respondent 76).

Above findings underscore that generation $Y$ participants in this study have different communication patterns at work vis-à-vis their non-generation $Y$ colleagues and managers. These patterns are exemplified by spontaneous and constant feedback. A tolerance for frankness from respondents in work-related interaction was also highlighted in replies. From another view, this could be perceived as a lack of confidence to take initiatives because of an increased reliance on feedback to make decisions.

\section{Conclusions}

Findings confirm many current understandings of generation Y's perceptions of hotel work

Importance of self-achievement

Several factors from replies underscore the value of self-achievement at work. The general tenor of the debate in the literature emphasises the importance for generation $Y$ workers to receive constant feedback as a means to progress. This is linked to generation Y's perception of self-achievement, which is reflected in this study. In the hotel context, by contrast, there is a degree of self-initiated work (such as taking initiatives to solve problems with guests) that could hinder this.

Congruence of work with personal values

Replies illustrated that participants in the study feel it is important to have their personal values enacted in the work environment. Findings from participants underscored the link between their ethical perceptions of organisations and the willingness to be employed by them. This paper sheds light on the importance of personal values for generation $Y$ employees in the hotel sector, which has traditionally focused on the guest as the centre of organisational values. This paper shows that there is also a reciprocal effect of employee and organisational congruency in terms of perceived values.

Importance of open communication

Replies suggest that study participants feel that being 'direct' is an effective method to communicate. This reveals that communication methods of generation $\mathrm{Y}$ in hotels can be at odds with those of other generations. Commonly, the literature has looked at the differences between generation $\mathrm{Y}$ and their managers. This study confirms findings from the literature which suggest that generation $Y$ prefers more direct communication styles that are unconventional to older generations. Findings on communication effects from this study can be added to the body of knowledge on experiences from the hotel sector. 
Findings shed new light on conceptual understandings of generation Y's expectations from hotel work

Generation Y's perception of time in hotel work is more fragmented than expected

Despite the prevalence of studies which suggest that generation $\mathrm{Y}$ is dependent on immediacy when interacting at work, findings from this study emphasise a reliance on face-to-face relationships. This could also be due to the nature of hotel work in general. However, despite long working hours and the predominance of face-to-face contact at work (notably with colleagues, managers, and guests), generation $Y$ hotel workers can also perceive high levels of temporal fragmentation versus non-generation $Y$ employers. This can be due to increased social and work demands due to a 'hyperactive' organisation of time. This suggests that generation $\mathrm{Y}$, despite their tendency to carry out multiple tasks simultaneously, adapt to the working patterns of non-generation $Y$ hotel employees.

Respondents discuss work tasks in terms of milestones and goals. This suggests that participants see structured job and career design as a way to motivate themselves. This also reveals that generation $Y$ is also more focused on temporal aspects of work. On a deeper level, this also indicates that there are learning periods that take more time than expected, such as when gaining experience for promotion. These understandings have broader repercussions on how generation $Y$ develops and maintains work relationships.

Generation Y's understanding of careers and work relationships contrasts with hotel industry norms

This paper reveals that generation $Y$ employees in hotels, in the sample drawn, contrast with industry norms which emphasise traditional, and more hierarchical work relationships. Tension emanating from organisational and cultural aspects of hierarchical relationships surfaced in replies. Findings from this study also shed light on the effects of work relationships in terms of careers. Cultural and organisational career norms in hotels are affected by deeply-rooted industry traditions. Generation $\mathrm{Y}$ in the hotel sector is confronted with a traditional model of hierarchy, within conventional working environments.

After evaluating replies, it became clear that the ensemble of understandings in terms of careers is made up of mono-perspectives. In findings, there is no illustration of how career perspectives could be understood by considering alternative views (e.g., those of managers or colleagues). Study findings brought to light incongruous expectations in terms of communication at work. For example, generation $Y$ workers expected more abundant communication than is expected from their non-generation $Y$ colleagues or 
managers. This underscores the crevasse which separates generation Y's mind set from those of other generations.

It could be argued that generation Y's career perceptions are incompatible with hotel sector practice. It is unclear how generation Y's career preferences will affect managerial practice. When viewed through the lens of role sets, generation $Y$ will seek to balance work- and non-work obligations. Findings show that their expectations are different than older generations. Employment features offered to generation $\mathrm{Y}$ hotel workers will influence their choice of employer and careers. Findings reveal a need for increased versatility in employment practice (such as flexible work patterns) and open communication between employees and employers to share expectations (such as increased feedback across hierarchical levels).

Findings open up the debate on the importance of generational awareness for employees and their colleagues and managers. This denotes a need for generation $Y$ and their nongeneration $Y$ colleagues and managers to gain increased understanding of generational aspects of work relationships. Findings from this study reveal that generation Y's current understanding of work in hotels is highly influenced by communication patterns and expectations from others in the workplace. Despite this, and paradoxically, generation $Y$ maintains parochial, self-centred views of careers.

From a wider angle, this paper demonstrates that generation Y's mind set is composed of contrasting dimensions. Examples include the emphasis on open communication in addition to a desire to maintain self-centred communication expectations of colleagues and managers. Despite insight revealed in this paper, many of these dimensions remain opaque to some degree. It could be argued that increased understanding of generational perspectives of work is difficult to capture because they remain within a generationalrelated 'state of mind.'

\section{$6 \quad$ Limitations}

This study was cross-sectional and could not track any change. There was also a lack of equal national groups in the sample. Discussions in this paper do not suggest that this study seeks to generalise. Rather, the paper aims to reveal insight from the group of people studied in the hotel industry context through their experiences. It could be beneficial in the future to use face-to-face interviews to probe. Methodologically, it could be valuable to opt for a highly inductive approach for future studies. This suggests picking up key topics for discussion during interviews and then exploring those topics in second interviews with the same and/or a larger number of participants. 


\section{References}

Adams, J. (1976), "The structure and dynamics of behaviour in organizational boundary roles." In Handbook of industrial and organizational psychological, ed. M. Dunnette, 1175-1199. Chicago: Rand McNally.

Barron, P., Maxwell, G., Broadridge, A., Ogden, S. (2007), "Careers in Hospitality Management: Generation Y's Experiences and Perceptions," Journal of Hospitality and Tourism Management, Vol. 14, No. 2.

Baum, T. (2006), "Reflections on the Nature of Skills in the Experience Economy: Challenging Traditional Skills Models in Hospitality," Journal of Hospitality and Tourism Management, Vol. 13, No. 2.

Cennamo, L., Gardner, D. (2008), "Generational differences in work values, outcomes and person-organisation values fit," Journal of Managerial Psychology, Vol. 23, No. 8.

Denzin, N., Lincoln, Y. (1998), Strategies of Qualitative Enquiry. London: Sage Publications, Ltd.

Eisner, S. (2005), "Managing Generation Y," SAM Advanced Management Journal, autumn.

Erickson, T. (2008), Plugged in, the Generation Y Guide to Thriving at Work. Boston: Harvard Business Press.

Fenich, G., Scott-Halsell, S., Hashimoto, K. (2011), "An Investigation of Technological Uses by Different Generations as it Relates to Meeting and Events: A Pilot Study," Journal of Conventions and Event Tourism, Vol. 12.

Giorgi, A. (1994), "A Phenomenological Perspective on Certain Qualitative Research Methods," Journal of Phenomenological Research, Vol. 25, No. 2.

Gursoy, D., Maier, T., Chi, G. (2008), "Generational differences: An examination of work values and generational in the hospitality gaps in the hospitality workforce," International Journal of Hospitality Management, Vol. 27.

Josiam, B., Devine, F., Baum, T., Crutsinger, C., Reynolds, J. (2007), "Attitudes to Work of Generation $Y$ Students in Hospitality Management: a comparative analysis of students in England, Scotland and Northern Ireland," Journal of Hospitality and Tourism Education, Vol. 22, No. 1.

Lewis, R., Mottier, E. (2012), "A 'hotel within a hotel' in Bangkok," Emerald Emerging Markets Case Study Collection, Vol. 2, Issue 8. 
Martin, C. (2005), "From high maintenance to high productivity,' Industrial and Commercial Training, Vol. 37, No. 1.

Maxwell, G., Broadbridge, A. (2010), “Generation Y's Career Expectations and Aspirations: Engagement in the Hospitality Industry," Journal of Hospitality and Tourism Management, Vol. 17.

Merton, R. (1957), "The role-set: problems in sociological theory, British Journal of Sociology, Vol. 8.

Michel, J., Kavanagh, M., Tracey, B. (2012), "Got Support? The Impact of Supportive Work Practices on the Perceptions, Motivation, and Behavior of Customer-Contact Employees," Cornell Hospitality Quarterly, Vol. 54, No. 2.

Ng., E., Schweitzer, L., Lyons, S. (2010), "New Generation, Great Expectations: A Field Study of the Millenial Generation," Journal of Business Psychology, Vol. 25.

Richards, L. (2009), Handling Qualitative Data. London: Sage Publications, Ltd.

Schein, E. (2010), Organizational Culture and Leadership. San Francisco: John Wiley and Sons.

Solnet, D., Hood, A. (2008), "Generation Y as Hospitality Employees: Framing a Research Agenda," Journal of Hospitality and Tourism Management, Vol. 15.

Solnet, D., Kralj, A. (2011), "Generational Differences in Work Attitudes, Evidence from the Hospitality Industry," Florida International University Review, Vol. 29, No. 2.

Solnet, D., Kralj, A., Kandampully, J. (2012), "Generation Y Employees: An Examination of Work Attitude Differences," The Journal of Applied Management and Entrepreneurship, Vol. 17, No. 3.

Terjesen, S., Vinnicombe, S., Freeman, C. (2007), "Attracting generation Y graduates, organisational attributes, likelihood to apply and sex differences," Career Development International, Vol. 12, No. 6.

Tulgan, B. (2009), Not Everyone Gets a Trophy: How to Manage Generation Y. San Francisco: John Wiley and Sons.

Twenge, J., Campbell, S. (2008), "Generational differences in psychological traits and their impact on the workplace," Journal of Managerial Psychology, Vol. 23, No. 8.

Twenge, J., Campbell, S., Hoffman, B., Lance, C. (2010), "Generational Differences in Work Values: Leisure and Extrinsic Values Increasing, Social and Intrinsic Values Decreasing," Journal of Management, Vol. 36, No. 5. 
Viard, J. (2011), Eloge de la mobilité. La Tour d'Aigues : Editions de l'Aube. 